\title{
ANASTOMOSE ESÔFAGO-JEJUNAL LÁTERO-LATERAL COM GRAMPEADOR LINEAR CORTANTE COMPLEMENTADA POR SUTURA MANUAL
}

\section{SIDE-TO-SIDE ESOPHAGO-JEJUNAL ANASTOMOSIS WITH LINEAR STAPLER COMPLEMENTED BY MANUAL SUTURE}

\author{
Paulo Sérgio Martins Alcântara, ACBC-SP ${ }^{1}$ \\ Nelson Fontana Margarido, TCBC-SP ${ }^{2}$
}

\section{INTRODUÇÃO}

Quando da realização de gastrectomia total, a maneira mais comum de reconstituição do trânsito do sistema digestivo, é através de anastomose esôfagojejunal término-lateral, em "Y de Roux" ${ }^{1}$. Pelo fato da gastrectomia total ser indicada em pacientes graves, essa anastomose é crítica, e envolve elevados índices de morbimortalidade, associada a prévia condição clínica $^{2}$. Qualquer que seja a técnica adotada, manual ou mecânica, essa anastomose apresenta elevados índices de complicações: estenose ou fístula; além do grande tempo consumido em sua execução, associado a dificuldade e desconforto da realização, por ser em local profundo e de difícil acesso.

Esta nota prévia tem o objetivo de apresentar variedade técnica desta anastomose ${ }^{3}$, cujo mérito será a de sua fácil realização, associada a mínima possibilidade de estenose ou fístula, além da maior rapidez, segurança, perfeita visualização e diminuição do custo operacional.

\section{TÉCNICA CIRÚRGICA}

Uma vez realizados todos os procedimentos cirúrgicos padronizados numa gastrectomia total, repara-se o futuro coto esofágico, antes da secção do esôfago com o estômago. É de fundamental importância, a certeza da não invasão tumoral da margem esofágica. Caso seja necessário, deverá se recorrer a cortes de congelação, para se ter essa garantia e segurança.

Como pré-requisito, abre-se o hiato esofágico em direção à porção posterior do mediastino. $\mathrm{O}$ coto esofágico será individualizado e mobilizado numa extensão de 4 a 5 centímetros. Essa mobilização deverá ser ampliada, quando houver invasão da neoplasia no esôfago.

A primeira alça jejunal, depois do ligamento suspensor do duodeno (ângulo de Treitz), é preparada de maneira convencional para o "Y de Roux". Essa alça com sua "bôca" distal fechada, por dois planos de sutura, será levada em direção cranial e em posição posterior ao coto esofágico, sendo então fixada com um ou dois pontos na parede posterior do esôfago, 5 a 6 centímetros da margem livre da "bôca" esofágica.

A seguir, realiza-se abertura, de todas as túnicas intestinais, na zona correspondente a margem contra mesenterial, logo abaixo do nível da margem livre da "bôca" esofágica. Esta abertura deverá ter extensão suficiente para a introdução, em sentido cranial, do garfo simples do grampeador linear cortante. $\mathrm{O}$ outro garfo do grampeador linear, dotado da alavanca de fechamento, é introduzido na luz esofágica e, após justaposição e articulação com o garfo colocado no delgado, é então disparado (Figura-1).

1. Médico Cirurgião do Hospital Universitário da Universidade de São Paulo, Mestre em Oncologia pela Faculdade de Medicina da USP

2. Professor Livre Docente e Associado do Departamento de Cirurgia da Faculdade de Medicina da USP 


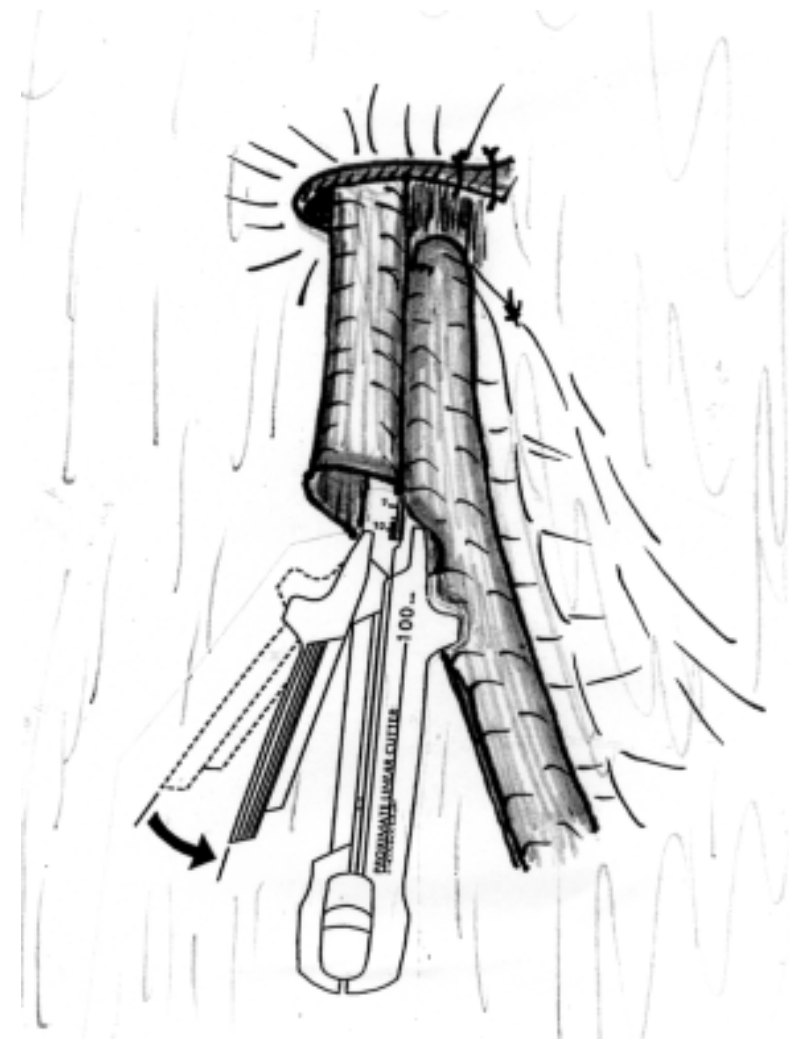

Figura 1 - Representação esquemática da justaposição do esôfago e da porção distal da primeira alça intestinal, e a aplicação dos dois garfos do grampeador linear cortante, no interior da luz de ambos os segmentos do sistema digestivo, instantes antes de ser disparado.

Retira-se o grampeador linear e está assim completado o tempo da sutura mecânica da anastomose e que corresponde à sua porção lateral. A equipe cirúrgica poderá visualizar com absoluta nitidez e facilidade esta parte da anastomose, que se tornou lateral, sem realizar trações ou torções das estruturas envolvidas (Figura-2). A anastomose esôfago-jejunal é completada de maneira manual. Com fios de poligalactina 910 , de calibre 3-0, é realizada sutura contínua total invaginante entre as margens livres do esôfago e da alça jejunal. Colocam-se pontos de reparos nas extremidades da sutura mecânica, junto à união do esôfago com o jejuno, e que quando tracionados em sentidos laterais transformam em linha única e transversal as margens livres das aberturas esofágica e jejunal, agora justapostas, o que facilita a conclusão da anastomose. Uma segunda sutura contínua, muscular e sero-muscular, também com fio de poligalactina 910 , é confeccionada com o objetivo de invaginar e sustentar o plano manual total.
Assim está concluída a anastomose esôfago jejunal látero-lateral, com grampeador linear cortante, e complementada com sutura manual em dois planos. Na Figura-3, em "A" estão representados dois pontos laterais, aplicados da base das duas linhas de grampeamento; em "B", a horizontalização e adequação das margens abertas do esôfago e jejuno, quando os pontos são tracionados em sentidos laterais, bem como o início da anastomose manual. Em "C", a complementação da anastomose manual. Em "D", a visão espacial da disposição da luz da anastomose: área semicircular menor, delimitada pela sutura manual entre as aberturas do esôfago e jejuno (porção anterior); área triangular com base inferior e vértice superior, delimitada pelas duas linhas de suturas mecânicas (porção lateral); e área semicircular maior, delimitada por toda a integridade restante da alça jejunal (porção posterior). A reconstrução do trânsito digestivo será completada com a correta finalização técnica do "Y de Roux".

\section{COMENTÁRIOS}

Apesar da popularização da anastomose mecânica esôfago-jejunal término-lateral, em

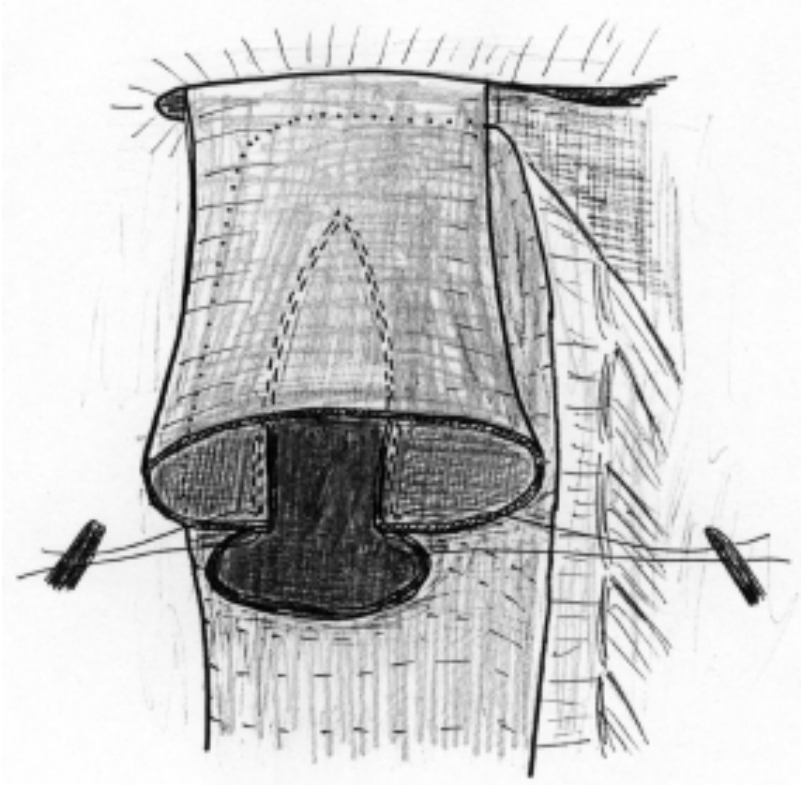

Figura 2 - Representação esquemática do segmento lateral da anastomose esôfago-jejunal, que corresponde a porção mecanicamente grampeada. 
A

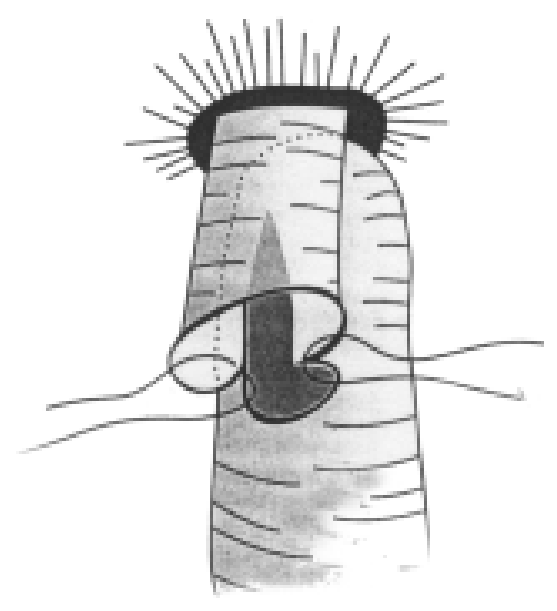

C

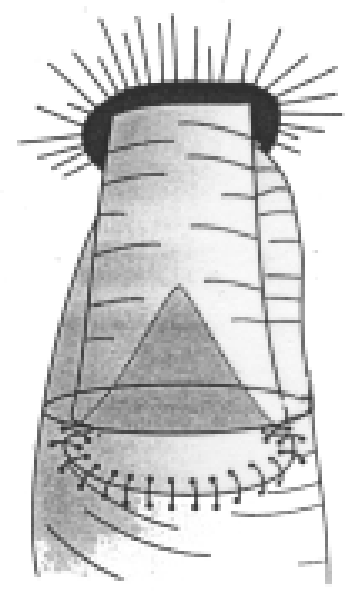

B

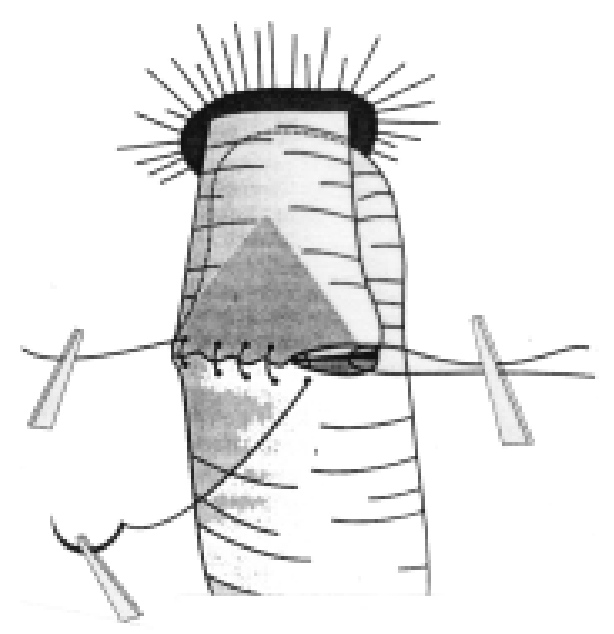

D

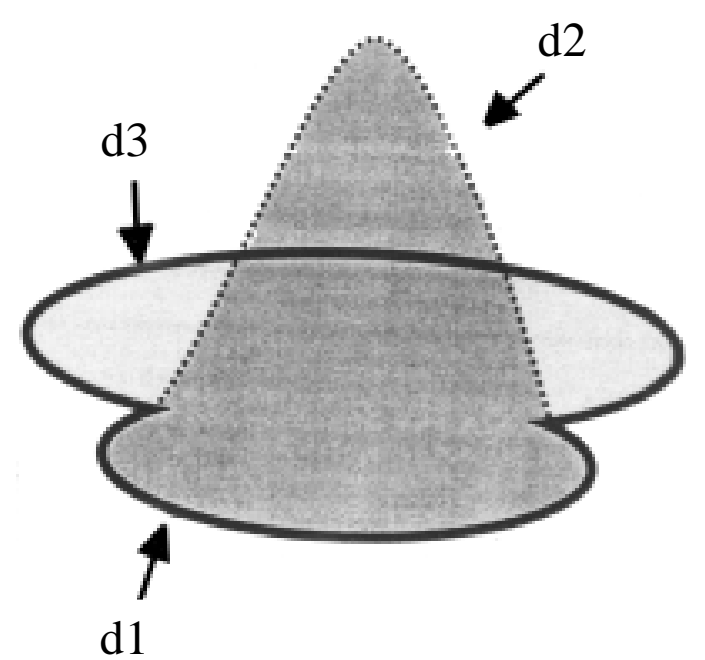

Figura 3 - Representação esquemática da anastomose esôfago-jejunallátero lateral, realizada com grampeador linear cortante, $e$ complementada com sutura manual (campos $A, B, C$ e D onde: $d 1=$ segmento anterior, $d 2=$ segmento lateral, $d 3=$ segmento posterior).

decorrência da sua rapidez de execução e da baixa incidência de fístulas, ainda persistem problemas técnicos e restrições econômicas ${ }^{4}$. Podem ocorrer dificuldades de utilização do grampeador cir- cular, representadas por fragilidade do esôfago, decorrente ou não da desvascularização do órgão, bem como da desproporção entre o calibre do grampeador e do diâmetro interno do tubo digestivo. 
Descuido na inserção de instrumental mais largo em relação as estruturas, pode lacerar a serosa intestinal, bem como esgarçar o esôfago ${ }^{4,5}$.

$\mathrm{Na}$ variante técnica ora apresentada, não existem essas possibilidades, bem como impedimento da ocorrência de estenoses com disfagia ou fístulas, que são complicações acompanhadas de elevados índices de morbimortalidade ${ }^{5}$. Essa proposta técnica aumenta o diâmetro da anastomose.
As vantagens dessa variante técnica são: visão direta e completa da sutura sem trações ou torções das estruturas; redução completa da possibilidade de estenose e conseqüente disfagia, mínima incidência de fístulas; rapidez e conforto em sua execução e redução do custo operacional, quando comparada a utilização do grampeador circular com o linear cortante. $\mathrm{O}$ grampeador linear, desde que bem utilizado, pode ser reutilizado com cargas adicionais, em até cinco vezes; com redução de $40 \%$ do custo em cada anastomose.

\begin{abstract}
One of the most difficult procedures in digestive-tract surgery is esophago-jejunal anastomosis following total gastrectomy. Cost/benefit analysis of this procedure justifies the use of mechanical staplers, in spite of their high cost. A technical variant of the side-to-side esophago-jejunal anastomosis is presented, which incorporates the use of a cutting linear stapler. Technical maneuvers are easy to perform, the cost of the cutting linear stapler is smaller than the circular ones, the amplitude of the anastomosis is wider and the likelihood of fistulae is smaller when compared to other techniques. The side-to-side esophago-jejunal anastomosis with the cutting linear stapler is always complemented by a manual suture.
\end{abstract}

Key words: Gastrectomy; Esophago-jejunal anastomosis; Mechanic soture

\title{
REFERÊNCIAS
}

1. Margarido NF, Tolosa EMC - Técnica Cirúrgica Prática, São Paulo, Atheneu, 2001, 40, p.337-343: Anastomoses mecânicas.

2. Chassin JL, Rifkind KM, Sussman B, Kassel B, Fingaret A, Drager S, Chassin P - The stapled gastrointestinal tract anastomosis: Incidence of postoperative complications compared with the sutured anastomosis. Ann Surg, 1978,188: 689-696.

3. Vogel SB - "Gastric cancer". In: Bland KI, Korakousis CP. Copeland III. E. - Atlas of surgical oncology. Philadelphia; W.B. Sunders Company; 1995, pp. 419-430.
4. Kataoka M, Masaoka A, Hayashi S, Honda H, Hotta T, Niwa T, Honda K - Problems associated withthe EEA stapling techique for esophagojejunostomy after total gastrectomy. Ann Surg, 1989, 209: 99-104.

5. Chassin JL, Rifkind KM, Turner JW. Erros and pitfalls in stapling gastrointestinal tract anastomoses. Surg Clin North Am, 1984, 64: 441-459.

Endereço para correspondência:

Dr. Nelson Fontana Margarido

Rua Itapeva, 378/CJ.22 - B.Vista

01332-000 - São Paulo - SP 